What's New from

Juntendo University, Tokyo

Juntendo Medical Journal

2017. $63(5), 318$

\title{
Foundation of Juntendo University Graduate School of Medicine Alumni Association
}

\author{
Secretariat General Isao Nagaoka \\ Professor of Department of Host Defense and Biochemical Research
}

Juntendo University Graduate School of Medicine has granted doctorates since 1963, and the total numbers of our two types doctorate holders (甲 Kou and 乙 Otsu) will reach 1,897 and 2,394, respectively, a total of 4,300, this year. In addition to graduates of Juntendo University School of Medicine, 835 of 230 other domestic universities/graduate schools and 311 of those in 26 countries other than Japan are included in these doctorate holders. To promote friendships among graduates of Juntendo University Graduate School characterized by such domestic and international diversity, as well as their development, Juntendo University Graduate School Alumni Association (English name: Club "Jin") was founded in December 2015.

According to its constitutions, those who obtained doctorates at Juntendo University Graduate School of Medicine and Professors belonging to the graduate school committees are entitled to become its regular members. As for students, those taking doctoral courses at the school are qualified as its student members. Thus, the alumni association is a large group, consisting of about 4,400 regular and 550 student members, a total of approximately 5,000 members.

The board of trustees is made up of the following members: President: CEO Hideoki Ogawa; VicePresidents: Faculty of International Liberal Arts Dean Eiki Kominami, President of Juntendo University School of Medicine Alumni Association Kou Morichika, Professor Emeritus Kiyoshi Sato, and President Hajime Arai; Executive Trustee: Faculty of Medicine and Graduate School of Medicine Dean Hiroyuki Daida; and Secretariat General: Isao Nagaoka. In addition, 19 甲 Kou and 24 乙 Otsu doctorate holders have been appointed as trustees (listed below without honorifics).

The future activities and operations of Juntendo University Graduate School of Medicine Alumni Association will be determined mainly by members of the board of trustees while considering other members' opinions.

$\begin{array}{llll}\text { Atsushi Kanai } & \text { Hiroshi Hashimoto } & \text { Yuichiro Yamashiro } & \text { Takeshi Miyano } \\ \text { Takao Okada } & \text { Yoshinari Takasaki } & \text { Takaaki Kameda } & \text { Takashi Yoshiike } \\ \text { Heii Arai } & \text { Kazuo Kaneko } & \text { Kaoru Obinata } & \text { Ryoji Tsuboi } \\ \text { Toshiaki Shimizu } & \text { Kazuhisa Takahashi } & \text { Masataka Sumiyoshi } & \text { Hiroyuki Kobayashi } \\ \text { Sachiko Miyake } & \text { Nobutaka Hattori } & \text { François Niyonsaba } & \text { Keiko Inatomi } \\ \text { Kenji Takamori } & \text { Kiyoshi Shiono } & \text { Takamitsu Matsudaira } & \text { Yasuo Hayashida } \\ \text { Hiroshi Tsuda } & \text { Haruo Ozaki } & \text { Masahiko Nozawa } & \text { Masafumi Suyama } \\ \text { Akira Murakami } & \text { Kazuhiro Sakamoto } & \text { Atsuyuki Yamataka } & \text { Chieko Hamada } \\ \text { Ran Yuping } & \text { Khalid Iqbal Butt } & \text { Yoko Tabe } & \text { Akihito Nagahara } \\ \text { Kiyoko Aoki } & \text { Volaluck Supajatura } & \text { Piti Palungwachira } & \text { Keisuke Sawaki } \\ \text { Daichi Suzuki } & \text { Norio Shimanouchi } & \text { Ayako Kudo } & \end{array}$

Copyright (C) 2017 The Juntendo Medical Society. This is an open access article distributed under the terms of Creative Commons Attribution License (CC BY), which permits unrestricted use, distribution, and reproduction in any medium, provided the original source is properly credited. doi: $10.14789 /$ jmj. 63.318 